\title{
Medizin ohne Grenzen?
}

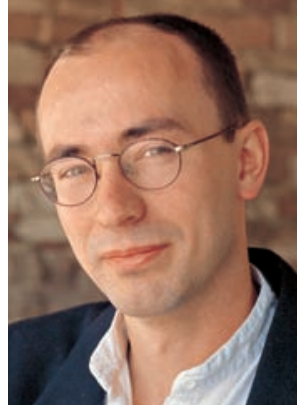

Dr. med. Dieter Schmid Redaktionsleitung
In jedem Medizinerleben gibt es Schlüsselsituationen, die ihn prägen. Der Moment, wenn erstmals ein Patient stirbt, gehört sicher dazu. Für mich war das in meinem PJ-Tertial in der Pneumologie. Die Patientin litt an einem Bronchialkarzinom. Ein Lungenflügel war schon entfernt, im anderen drückte eine Metastase kräftig auf den Hauptbronchus. Sie war kurzatmig, ihre Finger waren lehrbuchartig zu Trommelschlegeln verformt. Doch sie lachte, war guter Dinge und hoffte auf die Bestrahlungen. Als ich tags darauf die Station betrat, war sie tot: Ich war fassungslos. Wie konnte das passieren? Doch mein Stationsarzt Christoph schüttelte nur müde den Kopf, als ich ihn drauf ansprach. Nie vergesse ich seine Worte: „Glaub mir: Medizin kann viel. Aber sie kann sehr viel weniger, als sie selbst manchmal glaubt.“

In diesem Heft geben wir Ihnen zahlreiche Beispiele für die Macht der Medizin - aber auch für ihre Ohnmacht: Plastische Chirurgen können Männern, die als Frau geboren werden, heutzutage das ersehnte miktions- und erektionsfähige „Organ“ formen (S. 40). Auf der anderen Seite sind Transplanteure zur Untätigkeit verdammt, wenn ihnen keine Spenderorgane zur Verfügung stehen (S. 28). In den Kühlschränken der toxikologischen Institute in Deutschland liegen Antivena gegen jede nur denkbare Giftschlange - doch wenn jemand mit einem infizierten Katzenbiss zu spät zum Arzt geht, kann ihm unter Umständen alle Hightechmedizin dieser Welt nicht mehr helfen (S. 30). Neonatologen können extremen Frühchen heute sehr gut den Weg ins Leben ebnen. An einer naturgegebenen Grenze können aber auch sie nicht rütteln: Babys, die vor der 22. Schwangerschaftswoche auf die Welt kommen, sterben - außerhalb des Mutterbauchs können sie nicht überleben (S. 44).

Besonders häufig stößt man an Grenzen, wenn man in der Not- oder Entwicklungshilfe arbeitet. In unserem Titelthema „Traumjob oder Albtraum“ erzählen sechs Mediziner, die bei Hilfsorganisationen wie „Ärzte ohne Grenzen“ arbeiten, was sie motiviert - aber auch wie sie damit umgehen, angesichts mangelnder Ressourcen häufig machtlos zu sein (S. 8). Unsere Interviewpartnerin Dr. Monika Hauser, Trägerin des Alternativen Nobelpreises und Gründerin der Frauenhilfsorganisation medica mondiale, rät: „Man braucht Improvisationstalent, Frustrationstoleranz - und die Fähigkeit, abschalten zu können." Ein kluger Tipp! Vor allem die dritte Eigenschaft. Ab und zu mal abschalten, die Berufung vergessen und einfach „nur Mensch“ sein, ist für Mediziner geradezu überlebenswichtig - nicht nur in der Entwicklungshilfe. Auch im heimischen Klinikum. Auch im Studium! In diesem Sinne: Ich wünsche Ihnen einen guten Sommer! Ihr

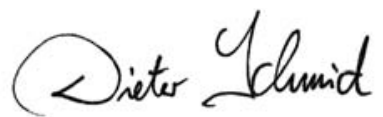

\section{ONLINE-UMFRAGE}

\section{Stationsarbeit - schon im Studium?}

Für Medizinstudenten in Frankreich beginnt im dritten Jahr der Ausbildung der klinische Studienabschnitt - genau wie in Deutschland. Der feine Unterschied: Französische Studenten arbeiten richtig mit. Sie sind eine echte Stütze für die Stationsärzte, denn die angehenden Mediziner nehmen Patienten auf und führen klinische Untersuchungen durch. Auch Nachtdienste und OP-Assistenzen gehören zum Alltag. Dadurch erarbeiten sie sich eine Routine, von der ein
Medizinstudent hierzulande nur träumen kann. Würden Sie sich auch einen solch „aktiven“ Zugang zur praktischen Medizin wünschen? Oder fürchten Sie, dass dadurch die Theorie auf der Strecke bleibt?

- Sollten deutsche Medizinstudenten genauso zur Mitarbeit in der Klinik verpflichtet werden wie ihre französischen Kommilitonen?

Stimmen Sie ab und sagen Sie Ihre Meinung unter: www.thieme.de/viamedici/aktuelles/aktion/ miniumfrage3_09.html
- Ergebnis der Umfrage in Via medici 2.09: Wir fragten, ob Sie in Studium und Klinik Rücksicht auf religiöse Kollegen nehmen würden. Ergebnis: 55\% der Teilnehmer sagen „Nein!“. Nur 41\% würden Kollegen unterstützen, die auch in Uni oder Klinik ihren Glauben praktizieren möchten. „Als Christ respektiere ich alle Menschen. Die Religion gehört für mich dazu“, meint ein Kommilitone. Ein Student hält dagegen: „Es erschwert das Zusammenleben enorm, wenn jeder Extrawünsche hat." Alle Kommentare unter: .../aktuelles/aktion/miniumfrage2_09.html 